DOI 10.37882/2223-2982.2021.09.11

\title{
МЕТОД КЕЙСОВ КАК ИНСТРУМЕНТ ПОДГОТОВКИ КАДРОВ В СФЕРЕ ТУРИЗМА
}

\section{THE CASE METHOD AS A TOOL FOR TRAINING PERSONNEL IN THE FIELD OF TOURISM}

\author{
Yu. Kireeva \\ O. Polyakova \\ L. Amozova \\ I. Okhotnikov
}

Summary: Each university teacher owns certain educational technologies, with the help of which he achieves the main goals facing modern education. One of these goals is to prepare students for professional activities in accordance with the requirements of the Federal State Educational Standard of Higher Education $3++$ [8].

When organizing a modern educational process, many methods and tools are used, while the teacher determines them independently. One such tool is the case method. The essence of this method is to find a solution to a problem, the description of which is presented in the format of a specific situation. Finding a solution to a problem, justifying it and presenting it means solving a case. Relatively recently, this method began to be used in the process of training tourist personnel.

The article examines the essence of the case method, highlights the main advantages over other teaching methods. The authors paid special attention to the signs of a "good case" and the classification of cases, which is necessary to understand the essence of the method and its role in organizing effective classes. As an example, the article presents a case that is proposed for solution to 3-4 year students of a tourism university. The authors considered the course and content of the lesson, in which it is necessary to solve the proposed case.

Keywords: training of tourist personnel, professional competence, case method, case-study, education, practice-oriented training, tourism.
Киреева Юлия Александровна

К.п.н., дочент, ФГБОУ ВО «Российский государственный университет туризма и сервиса» (РГУТИС); Высшая школа

туризма и гостеприимства

kireeva.ya@mail.ru

Полякова Офелия Робертовна

К.п.н., дочент, ФГБОУ ВО «Российский государственный гуманитарный университет» (РГГУ)

avt374473@mail.ru

Амозова Лариса Николаевна

К.и.н., дочент, МГУ им М.В. Ломоносова, Москва.

amozova.larisa@yandex.ru

Охотников Илья Викторович

К.э.н., дочент, Российский университет транспорта (МИИТ), Москва roat.miit@mail.ru

Аннотация: Каждый вузовский преподаватель владеет определёнными образовательными технологиями, с помощью которых достигает основных целей, стоящих перед современным образованием. Одна из таких целей подготовка обучающихся к профессиональной деятельности в соответствии с требованиями ФГОС В0 3++ [8].

При организации современного учебного процесса применяется много методов и инструментов, при этом преподаватель определяет их самостоятельно. Один из таких инструментов - метод кейсов. Суть данного метода заключается в поиске решения какой-либо проблемы, описание которой представлено в формате конкретной ситуации. Найти решение проблемы, обосновать его и представить - означает решить кейс. Сравнительно недавно данный метод стал использоваться в процессе подготовки туристских кадров.

В статье рассмотрена сущность метода кейсов, выделены основные преимущества перед другими методами обучения. Особое внимание авторы уделили признакам «хорошего кейса» и классификации кейсов, что необходимо для понимания сути метода и его роли в организации эффективных занятий. В качестве примера в статье представлен кейс, который предлагается для решения обучающимся на 3-4 курсе туристского вуза. Авторами рассмотрен ход и содержание занятия, на котором необходимо решить предложенный кейс.

Ключевые слова: подготовка туристских кадров, практико-ориентированное обучение, профессиональные компетенции, метод кейсов, case-study, образование, туризм.

либо сертификат о прививке, либо медицинский документ, подтверждающий перенесенную болезнь, либо отрицательный ПЦП-тест. Статистические данные свидетельствую о падении числа туристов во всем мире. Так, например, в январе - сентябре 2020 г. с целью туризма Россию посетило всего 12900 человек (поток иностранцев снизился на 73\%).

На начало 2020 г. в туристской отрасли по всему миру 
было занято 330 млн человек (World Travel \& Tourism Council). Ограничения, введенные всеми странами в связи с распространением COVID-19, а также изменения реальности и изменения в структуре туристского потребления повлияли на изменения индустрии туризма в целом: сформировалось несколько трендов, которые, скорее всего, останутся актуальными достаточно долго. Один из современных трендов - активное развитие внутреннего туризма, а также увеличение спроса на поездки в рамках экологического туризма. Таким образом, подготовка соответствующих специалистов актуальна как никогда [7].

С учетом современных тенденций преподаватель должен найти такие методы и инструменты преподавания профильных туристских дисциплин, которые бы раскрыли и максимально развили творческий потенциал личности, заинтересовали обучающихся самостоятельно изучать тот или иной вопрос. Одним из подобных инструментов является метод кейсов, активно применяемых преподавателями в процессе обучения в туристских вузах.

Чаще всего метод кейсов используется на 3-4 курсах по программам бакалавриата. Основная причина этого заключается в том, что студенты младших курсов пока не обладают нужным объемом знаний для решения кейсов (в большинстве случаев для решения кейса нужны знания в области туроперейтинга, экономики, маркетинга, менеджмента), не умеют уверено и ясно излагать свою позицию по рассматриваемой в кейсе проблеме, не обладают достаточными навыками ведения дискуссии и публичных выступлений. Таким образом, применение метода кейсов на старших курсах бакалавриата более эффективно.

Необходимо отметить, что метод кейсов эффективен не только на семинарских и практических занятиях с целью формирования необходимых компетенций. Данный метод можно использовать и в качестве инструмента для проверки полученных знаний и сформированных компетенций, т.е. во время проведения зачетов и экзаменов.

Сегодня в России проходят чемпионаты по решению кейсов, организовываются тематические клубы [3].

\section{Материалы и методы исследования}

В процессе подготовки данной статьи были проанализированы работы отечественных и зарубежных преподавателей и практиков: С.Ю. Мычка, М.А. Шаталова, С.С. Гасанова, М.А. Долгорукова, В.И. Тимохова, П.Эксмана, Л.В. Рейнгольда, Л.И. Барнса и др.

Значительный вклад в разработку и внедрение этого метода внесли Г.А. Брянский, Ю.Ю. Екатеринославский, О.В. Козлова, Ю.Д. Красовский, В.Я. Платов, Д.А. Поспелов, О.А. Овсянников, В.С. Раппопорт и др.
Методы, используемые в работе:

- анализ литературы по заявленной теме;

- сравнительный анализ теорий;

- анализ содержания методических материалов туристских вузов, представленных в открытом доступе;

- обобщение передового педагогического опыта.

\section{Результаты исследования и их обсужление}

Изменение общей образовательной концепции в сторону компетентностно-ориентированных методик обучения, можно без преувеличения назвать существенным стимулом для внедрения инновационных технологий и методик, в первую очередь, в рамках высшего профессионального образования. Поиск и применение эффективных методов обучения актуален как никогда: прежде всего это связано с модернизацией образования в нашей стране. Метод кейсов или case study, достоинства которого максимально полно раскрываются в рамках преподавания экономических дисциплин, привлек внимание отечественной образовательной среды лишь ближе к концу XX века [6].

Сущность метода кейсов, как инструмента решения конкретных ситуаций заключается в проработке оптимальной стратегии разрешения конкретной практической ситуации, смоделированной с опорой на фактический материал, предусматривающая последующий всесторонний анализ перспектив реализации данной стратегии в различных условиях, в случае изменения параметров и пр. [5].

Среди несомненных достоинств использования метода при подготовке специалистов можно выделить:

- возможность ознакомления студентов с приближенным к реальным экономическим, организационным и социальным аспектами модели предприятия;

- возможность детального и всестороннего структурного анализа проблемы;

- возможность окунуться в рамках смоделированной ситуации в атмосферу цейтнота, давления ответственности за результат решения.

- возможность получения в свое распоряжение определенных материалов в рамках решения поставленной в процессе обучения по методу кейсов задачи;

- возможность получения опыта работы над решением задачи в команде, коллективной выработки итогового решения, его обрамления и презентации;

- возможность взгляда на другие способы решения аналогичной проблемы и их обоснование.

В настоящее время внедрение данного метода обучения в практику высшего образования сферы туризма является крайне актуальной задачей, что обуславлива- 
ется общим курсом развития образовательной сферы, ее ориентированности в большей степени на формирование профессиональных компетенций, развитие личностных способностей, чем на получение определенных знаний. Особое внимание при таком подходе уделяется формированию способности к обучению, гибкости мышления, умению анализировать большие массивы данных. Актуальность внедрения метода кейсов также продиктована обновлением требований к уровню специалиста, что подразумевает наличие способности оптимального и эффективного поведения в разнообразных ситуациях, умения эффективного и оптимального подхода в кризисных условиях.

Метод кейсов активно используется известными вузами России в процессе подготовки кадров, прежде всего для сферы экономики. Использование данного метода для подготовки специалистов позволяет интенсифицировать интерес обучающихся к образовательному процессу, что также способствует улучшению понимания экономических законов, позволяет сформировать коммуникативные и творческие навыки в рамках решения задач по принятию решений.

Яркой отличительной особенностью метода кейсов можно назвать создание, так называемой проблемной ситуации на основе реальных фактов. Если изначально метод был создан для изучения экономических дисци- плин, то на сегодняшний день он получил куда более широкое распространение в рамках изучения таких дисциплин, как: юриспруденция, иностранные языки, медицина и пр.

Для организации эффективного учебного процесса с применением метода кейсов необходимо два условия: «хороший кейс» и определенная методика его применения на занятии [1].

Анализ педагогической литературы позволил выделить основные признаки «хорошего кейса» (рисунок 1).

Кейсы классифицируются по различным основаниям (таблица 1).

Независимо от того, какой кейс предлагается для решения, он содержит:

- введение, в котором представлена общая информация о кейсе. Введение также может содержать исходные данные исследования, понятийный аппарат, перечень вопросов для рассмотрения;

- основную часть - проблему для решения, реальную ситуацию, требующую разрешения;

- дополнительные материалы для решения - данный элемент носит вариативный характер, содержит схемы, таблицы, фотографии, карты и т.д. Для каждого кейса объем и содержание данных материалов определяется автором.

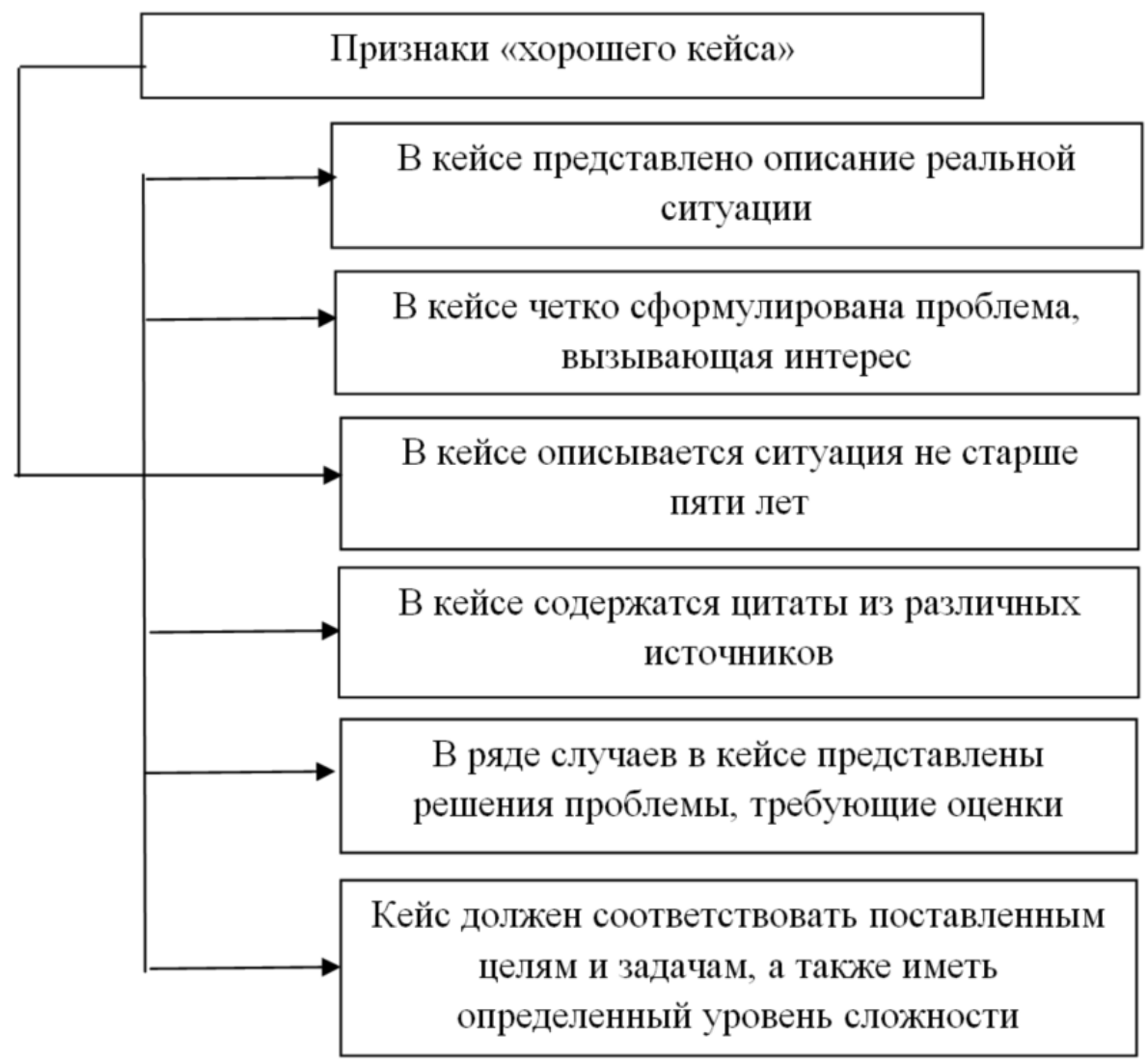

Рис. 1. Основные признаки «хорошего кейса» 
Таблица 1.

Классификация кейсов

\begin{tabular}{|c|c|c|}
\hline № $\Pi / \Pi$ & Основание для классификации & Виды кейсов \\
\hline 1 & Уровень сложности & $\begin{array}{l}\text { - Иллюстративные учебные ситуации } \\
\text { - Учебные ситуации с четко сформулированной проблемой } \\
\text { - Учебные ситуации для выявления и самостоятельной формулировки проблемы } \\
\text { - Прикладные упражнения }\end{array}$ \\
\hline 2 & Цель и задачи обучения & $\begin{array}{l}\text { - 0бучающие анализу и оценке } \\
\text { - Обучающие решению проблем и принятию решений } \\
\text { - Иллюстрирующие проблему в целом }\end{array}$ \\
\hline 3 & Наличие сюжета & $\begin{array}{l}\text { - Сюжетные } \\
\text { - Бессюжетные }\end{array}$ \\
\hline 4 & Жанровые особенности & $\begin{array}{l}\text { - Изложение материала от прошлого к настоящему } \\
\text { - Кейсы-воспоминания } \\
\text { - Прогностические }\end{array}$ \\
\hline 5 & Субъект & $\begin{array}{l}\text { - Личностные } \\
\text { - Организационно-институционные } \\
\text { - Много-субъектные }\end{array}$ \\
\hline 6 & 0бъём кейса & $\begin{array}{l}\text { - Малый (1-3 страницы) } \\
\text { - Средний (4-10 страницы) } \\
\text { - Объемный (нескольких десятков страниц) }\end{array}$ \\
\hline 7 & Наличие приложений & $\begin{array}{l}\text { - С приложениями } \\
\text { - Без приложений }\end{array}$ \\
\hline 8 & Методическая часть & $\begin{array}{l}\text { - Вопросные кейсы } \\
\text { - Кейсы-задания }\end{array}$ \\
\hline 9 & Степени воздействия основных источников & $\begin{array}{l}\text { - Практические кейсы } \\
\text { - Обучающие кейсы } \\
\text { - Научно-исследовательские кейсы }\end{array}$ \\
\hline 10 & Способ представления материала & $\begin{array}{l}\text { - Печатный } \\
\text { - Мультимедийный } \\
\text { - Видео кейс }\end{array}$ \\
\hline
\end{tabular}

Как показывает практика, метод кейсов чаще всего применяется в аудитории, на занятии, когда деятельность обучающихся, направленная на решение проблемы, направляется преподавателем, при этом осваиваются теоретические знания, практические навыки и формируются профессиональные компетенции.

В таблице 2 представлен ход и содержание занятия по одной из профильных дисциплин по направлению подготовки 43.03.02 Туризм с применением метода кейсов.

Данный кейс может быть использован на таких дисциплинам как «Основы туризма и туристской деятельности», «Маркетинг», «Инновационные технологии в индустрии туризма», «Технологии и организация услуг в туризме», «Виды и тенденции развития туризма», «Туристско-рекреационное проектирование» и др. Данные учебные дисциплины включены в учебные планы большинства вузов, реализующих ФГОС по направлению Туризм уровня бакалавриат. Перечисленные дисциплины преподаются на разных курсах, в связи с этим кейс также можно предложить для решения студентам разных курсов, дополнив его дополнительной информацией, перечнем заданий, усложнив его. В том случае, когда кейс имеет объем более 10 страниц, рекомендуется предоставить его обучающимся для ознакомления заранее, а в аудитории после представления сразу же перейти к работе малых групп.

С учетом актуальности систематизации теоретических принципов применения современных педагогических инноваций, нельзя не заметить, что применение метода кейсов в процессе подготовки студентов по многим профильным направлениям является вопросом, требующим изучения и внимательной проработки. То же касается и подготовки кадров для туристской сферы. Важно отметить, что в рамках внедрения метода в существующие образовательные программы подготовки специалистов сферы туризма, в которой крайне важна ситуационная реакция на меняющиеся условия, необходимо действовать уверенно и оперативно. Также необходимо 
Таблица 2.

Ход и содержание занятия с применением метода кейсов

\begin{tabular}{|c|c|c|c|c|}
\hline № $\Pi / \Pi$ & Этапы занятия & Характеристика этапов занятия & Время & Методическое обеспечение \\
\hline 1 & Ведение & $\begin{array}{l}\text { - Преподаватель приветствует обучающихся } \\
\text { - Проверяет готовность обучающихся к занятию } \\
\text { - Организация малых групп из обучающихся }\end{array}$ & 5 минут & - \\
\hline 2 & $\begin{array}{l}\text { Ознакомление с } \\
\text { текстом кейса }\end{array}$ & $\begin{array}{l}\text { Обучающиеся знакомятся с описанием кейса } \\
\text { В настояшее время одна из стратегических задач администрации } \\
\text { Ивановской области - расширение в области современного турист- } \\
\text { ского комплекса, специализирующегося на улучшении привлекатель- } \\
\text { ности региона сточки зрения привлечения туристов благодаря } \\
\text { эффективному применению культурных, исторически и природных } \\
\text { ресурсов. } \\
\text { Одним из самых популярных туристских иентров Ивановской об- } \\
\text { ласти является город Плес, который ежегодно посещают порядка } \\
300 \text { тысяч гостей. Плес должен стать центтральной точкой данного } \\
\text { комплекса. Предполагается расширение туристской инфраструкту- } \\
\text { ры по побережью реки Волги и рядом с ней (кафе, гостиничный бизнес, } \\
\text { кофейни, музеи), постоянного сообщения по реке между городами } \\
\text { побережья Волги. Ключевое внимание следует уделить поддержке } \\
\text { информационного сообщения. } \\
\text { Принимая во внимание зарубежный опыт туризма, накопленныий } \\
\text { опыт развития новых туристских сфер, определен следующий порт- } \\
\text { фель базовых разновидностей туризма: культурный, оздоровитель- } \\
\text { ный, автобусный, водный туризм. }\end{array}$ & 10 минут & $\begin{array}{l}\text { - Кейс может быть представлен в } \\
\text { печатном виде или в виде презентации } \\
\text { - Для удобства работы возможно } \\
\text { предоставление в двух форматах }\end{array}$ \\
\hline 3 & $\begin{array}{l}\text { Формулировка } \\
\text { заданий кейса }\end{array}$ & $\begin{array}{l}\text { 1. Какие муниципальные образования (кроме Плеса) в Ивановской } \\
\text { области необходимо включить в региональное туристское направле- } \\
\text { ние и почему? } \\
\text { 2. Сформулируйте рекомендации по развитию туризма в выбранном } \\
\text { муниципальном образовании. }\end{array}$ & 5 минут & $\begin{array}{l}\text { Вопросы могут быть предоставлены } \\
\text { в печатном виде каждой группе об- } \\
\text { учающихся }\end{array}$ \\
\hline 4 & Работа с кейсом & $\begin{array}{l}\text { - Работа обучающихся в малых группах по формированию предло- } \\
\text { жений по заданиям кейса } \\
\text { - Поддержание преподавателем делового настроя среди обучаю- } \\
\text { щихся }\end{array}$ & 30 минут & $\begin{array}{l}\text { - Текст кейса в печатном виде } \\
\text { - Карта региона } \\
\text { - Путеводители по городу и региону } \\
\text { - Доступ к сети Интернет }\end{array}$ \\
\hline 5 & $\begin{array}{l}\text { Представление } \\
\text { результатов }\end{array}$ & $\begin{array}{l}\text { - Каждая группа обучающихся представляет свои решения кейса } \\
\text { - В ходе совместной дискуссии возможна выработка единого ком- } \\
\text { плекса решений }\end{array}$ & 35 минут & $\begin{array}{l}\text { - Решение кейса обучающиеся могут } \\
\text { представить устно. } \\
\text { - Сообщение может быть дополнено } \\
\text { презентацией в формате PowerPoint }\end{array}$ \\
\hline 6 & $\begin{array}{l}\text { Подведение } \\
\text { итогов }\end{array}$ & $\begin{array}{l}\text { - Анализ и оценка решений кейса, предложенных каждой группой } \\
\text { - Оценка преподавателем вклад каждой группы обучающихся в } \\
\text { подготовку решений по кейсу }\end{array}$ & 5 минут & $\begin{array}{l}\text { Материалы, представленные малыми } \\
\text { группами обучающихся }\end{array}$ \\
\hline
\end{tabular}

активно использовать метод кейсов в рамках системы дополнительного профессионального образования, что немаловажно именно в контексте реализации программ переподготовки специалистов. Для специалистов туристской сферы получение навыков принятия обоснованных решений на уровне управления предприятием в меняющихся внешних условиях неопределенной внешней среды является крайне важным, что продиктовано особенностями организационной структуры компании.

При использовании метода кейсов в процессе подготовки туристских кадров, необходимо добиться его органичной взаимосвязи с прочими методами обучения, включая также и традиционные, формирующими у студентов базис нормативных знаний. Ситуационное обучение позволяет студенту освоить поиск и использование знаний в условиях стремительно меняющейся ситуации, что способствует развитию гибкости мышления, умению проводить анализ ситуации с учетом множества факторов, рассматривать ситуацию под разными углами и в разных плоскостях, пониманию того факта, что в решении отдельно взятой задачи не всегда выбранный путь является единственно верным [2]. 
Метод кейсов является отличным инструментом решения многих задач профессионального образования, среди которых и погружение студентов в условия практической деятельности в профессиональной туристской среде, и подготовка специалистов, ориентированных на нахождение оптимальных путей достижения поставленных целей, развитие критического мышления, ознакомление студентов с будущей практической деятельностью на предприятиях сферы туризма. Одним из главных преимуществ метода можно назвать получение студентами в процессе обучения практических навыков, а также развитие лидерских способностей, качественное повышение уровня взаимодействия при работе в команде. Кроме того, посредством внедрения метода кейсов в образовательный процесс можно активизировать развитие интеллектуального капитала, дать толчок формированию полноценной системы профессиональных качеств будущего сотрудника сферы туризма, но также общечеловеческих и моральных ценностей личности.

Тем не менее, чрезмерное увлечение ситуационным анализом может привести к тому, что будущий специалист окажется без необходимого «нормативного скелета», все его знания будет сводиться к знанию множества ситуаций без определенного методологического принципа или системы [4]. Вероятность подобного исхода обучения возможно минимизировать путем нахождения грамотного подхода к апробации метода в рамках образовательного процесса.

Применение метода кейсов при подготовке специалистов сферы туризма должно быть обоснованным и обеспеченным методически. Этого необходимо добить- ся не только на уровне организации процесса подготовки по специальным образовательным программам, но также на уровне каждого отдельного преподавателя. Внедрение обозначенного метода в подготовку туристских кадров необходимо осуществлять на основе экспертной оценки туристских специальностей, на уровне разделов и отдельных учебных дисциплин, где использование метода кейсов будет эффективнее, в сравнении с традиционными обучающими технологиями. Решение данных вопросов должно являться предметом обсуждения на уровне методического совета, а также являться одной из ключевых целей повышения квалификации преподавательского состава.

\section{Зак^ючение}

Метод кейсов - один из эффективных инструментов современного образования. Его эффективность обусловлена следующими преимуществами: практическая направленность, интерактивный формат, возможность освоения профессиональных компетенций, необходимых для работы.

Для реализации методов кейсов в учебном процессе необходимо тщательно отбирать кейсы для занятий, а также использовать их на регулярной основе, постепенно повышая их сложность.

Применение метода кейсов способствует развитию творческой познавательной деятельности обучающихся, повышению способности к обучению, развивает навыки работы в команде, мотивирует к поиску эффективного решения сформулированной проблемы.

\section{ЛИТЕРАТУРА}

1. Блинов, А.О. Интерактивные методы в образовательном процессе. Учебное пособие / Андрей Блинов. - М.: Научная библиотека, 2014. - 649 с.

2. Долгоруков А.М. Метод case-study как современная технология профессионально-ориентированного обучения. URL: http://www.evolkov.net/case/case. study.html

3. Ефремцева, Т.H. Travelskills как оценка качества подготовки кадров для индустрии туризма в России / Т.Н. Ефремцева, Ю.А. Киреева // Вестник РМАТ. 2019. - № 3. - С. 35-40.

4. Заводчиков Е.В. Методика применения кейс - технологии как условие продуктивного обучения в условиях реализации ФГоС//развитие непрерывного педагогического образования в условиях реализации профессионального стандарта/ Материалы сетевого семинара ЦПК ЛГУ им. А.С. Пушкина, СПБ ИУо РАО и СПб ГБП ОУ ИПЛ для работников общего и профессионального образования, управления образованием. Изд. Межрегиональный центр инновационных технологий в образовании (Киров). 2017. С. 126-131

5. Михайлова Е.А. Кейс и кейс-метод / Е.А. Михайлова. - М.: Центр маркетинговых исследований и менеджмента, 2015. - 136 с.

6. Наумова М. Использование метода case-study в преподавании экономических дисциплин в высших учебных заведениях / М. Наумова, Л. Гладкова. - К., 2013. $-217 c$.

7. Полякова, О.Р. Особенности процесса подготовки туристских кадров на фоне пандемии COVID-19 / 0.Р. Полякова // Современные проблемы туризма и сервиса: Сборник статей научных докладов по итогам Всероссийской научно-практической конференции, Москва, 29 апреля 2021 года / Под редакцией 0.Е. Афанасьева, Е.В. Юдиной. - Москва: Российский государственный университет туризма и сервиса, 2021. - С. 285-292.

8. Evaluating the quality of vocational tourism education within the context of international standards / Yu.A. Kireeva, T.N. Efremtseva, E.N. Tregubenko [et al.] // Revista Inclusiones. - 2020. - Vol. 7. - No S2-4. - P. 56-68.

( ) Киреева Юлия Александровна (kireeva.ya@mail.ru), Полякова Офелия Робертовна (avt374473@mail.ru),

Амозова Лариса Николаевна (amozova.larisa@yandex.ru), Охотников Илья Викторович (roat.miit@mail.ru).

Журнал «Современная наука: актуальные проблемы теории и практики» 